\title{
Communities on Social Networking Sites: Testing a Socio-Cognitive Model for Brand Page Usage
}

\author{
Christopher H. Ruehl \\ University of Fribourg, Switzerland \\ christopher.ruehl@unifr.ch
}

\author{
Diana Ingenhoff \\ University of Fribourg, Switzerland \\ diana.ingenhoff@unifr.ch
}

\begin{abstract}
In recent years many corporations have become active on social networking sites (SNS). However, our understanding about how and why community members use corporate pages on SNS has not kept pace. In our study, we test a socio-cognitive model of brand page usage to investigate users' incentives to consume and interact with corporations on Facebook. In order to do so, we conducted an online survey $(N=1294)$ and analyzed our data using exploratory (EFA) and confirmatory factor analyses (CFA). We find that motives among the activity, self-reactive-novel and monetary incentive dimension drive consumption behavior; incentives among the status, practical-novel and selfreactive dimension drive participation; and finally, social, self-reactive and status incentives were found to stimulate production behavior on Facebook brand pages. The implications for community management on SNS will be discussed at the end of the paper.
\end{abstract}

\section{Introduction}

Social networking sites (SNS) can generally be described as web applications, which enable users to build up and maintain their own, personalized networks for information sharing and communication with others [1]. Due to the popularity, high usage numbers and generally high diffusion of SNS in today's society, many corporations have discovered such applications for communication with their publics.

Corporate pages on SNS are called brand pages. They allow corporations to share their business, products and services with other users and create a virtual community around their brand by having people "like", "follow" or "subscribe" to a corporate page and consequently become "fans" and "followers" of a company profile $[2,39,40]$.

From this perspective, we can describe a brand page community as the user network structure of a corporate page on a SNS, including all users of the web application who have access to the company profile.
Community, thus, refers to the nature of the relationship between SNS users and corporations [3]. The relationship is based on user interests, skills or concerns, rather than aspects of geographic location [4].

From a corporate communication management point of view, it can be argued that SNS offer great potential to build community relationships by communicating with stakeholders and engage in discussions with (potential) customers, shareholders and other social groups.

In the past years, communication scholars started to investigate how and why individuals use corporate brand pages, as well as the underlying antecedents driving brand page behavior [2, 5, 6, 7]. However, existing studies often employ qualitative approaches with rather small sample sizes [2, 7]. In addition, these studies were often conducted in different parts of the world, with very little reference to one another, making a generalization of the findings rather difficult.

As a result, we are facing a lack of studies which allow us to gain a more general, quantifiable understanding about why and how online communities use brand pages. Our study addresses this gap by testing three distinct models for three different types of SNS brand page usage (consumption, participation and production) developed and pre-tested in an earlier study [8]. The models build on a combined theoretic approach of uses-and-gratifications (U\&G) [9] and social cognitive theory (SCT) $[10,11]$ being applied to SNS usage [8, $12]$.

Our study data results from an online survey $(\mathrm{N}=1294)$ and was analyzed using confirmatory factor analysis to test the three models of brand page usage with a large data set, not previously applied for model development. The implications of the findings for further investigations into community management, as well as the practice of corporate communication on SNS will be discussed. 


\section{Theoretical approach}

\subsection{The $U \& G$ approach and its application to corporate Facebook page usage}

The U\&G approach [9] is one of the oldest and mostly applied perspectives to investigate patterns of media ddfdfdfdfuse. The approach builds on the assumption that individual's use of any type of media is purposeful and goal-oriented. By turning to media offers, individuals seek to satisfy particular needs, which can be described as gratifications [13]. These gratifications vary among individuals and can be divided into two groups: gratifications sought (GS) and gratifications obtained (GO). GS are defined as the motives of individuals to consume certain media. GO represent the gratifications which actually result from media use. There is also the possibility of experiencing a discrepancy between what was sought and obtained, which indicates that media consumption does not necessarily lead to a satisfaction of GS [14]. Therefore, individuals will evaluate the perceived future discrepancy between the GS and GO before turning to certain media, in order to have a majority of needs met. Over time, the result of this evaluation is cognitively processed as media knowledge and will be drawn upon in future situations of media choice [15].

So far, most investigations which employed the U\&G approach to studies of internet and Web 2.0 gratifications adopted items retrieved from previous studies on motivations for traditional media use, yet traditional media gratifications often seemed to inadequately represent the reasons driving internet usage $[7,16,17,18]$. LaRose et al. $[11,12]$ were among the first to theoretically advance U\&G with SCT [10] in order to explain the often-observed relationship between media gratifications and media use more adequately, and thus increase the explanatory power of the U\&G paradigm.

\subsection{The advancement of the $U \& G$ approach with SCT}

Bandura's [10] social cognitive theory (SCT) had originally been conceptualized as a learning theory, which has ever since often been applied to studies of media usage and media behavior [19].

SCT posits a reciprocal effect between individuals, their behavior and the environment. Human behavior is viewed as an observable act and the performance of such behavior is determined by its expected consequences, also called expected outcomes. The latter are formed through cognitive processes, most importantly by observing and imitating the behavior of others in one's social environment (vicarious learning) or by learning from experience (enactive learning). Following this notion, the use of any type of media will also be determined by expected outcomes, and, can thus be described as overt media behavior.

For the concept of GS from U\&G, this means that gratifications sought can be conceptualized as expected outcomes of media behavior. The expected outcomes serve as motivations for media behavior, whereas motivations are called incentives in SCT terminology. Bandura [10] differentiates six incentive dimensions, constituting broad categories in which to group media usage motivations [12]: Activity incentives aim to satisfy the wish to take part in enjoyable and fun activities and mainly include entertainment gratifications. Monetary incentives describe financial motives, especially money-generating and money-saving motives. Incentives to search for new information to acquire knowledge are called novel incentives, whereas social incentives relate to interactions with others to discuss or exchange opinion. Expected outcomes to regulate one's mood or emotional state, as well as a state of cognitive discontent can be subsumed under selfreflective incentives. Finally, status incentives point to motives of social power, hierarchy and image cultivation.

Recently, two additional incentive dimensions were identified to especially apply to Web 2.0 behavior [7, 20]. The authors found ideological incentives, which refer to behavior driven by an individual's personal ideals and values, such as altruism, as well as practical incentives. The latter can be described as meta-outcome expectations since they describe motives, which catalyze outcome expectations, rather than posing as unique motives by themselves, i.e. laziness, comfort, convenience or flexibility.

Research shows that the theoretic combination of U\&G with SCT has yielded better explanation rates for internet and Web 2.0 use than most traditional U\&G studies $[12,20]$. In addition, the advancement provides a theoretical foundation for the U\&G approach, which has long been criticized for being theoryless [42]. Therefore, we used this perspective as well for the development of our models of brand page usage [8] to be tested in this study.

\subsection{Web 2.0 usage types}

Most studies investigating the usage of corporate offerings on SNS are interested in user engagement with brand pages, and thus, subsume any type of be- 
havior exceeding mere passive usage, such as reading corporate posts under the engagement label $[2,6,21$, 22]. However, it can be argued that SNS allow for a variety of different usage types which can be further specified. Therefore, our models apply Shao's [23] conceptualization of audience activity on a continuum of interaction from low to high. The author differentiates three usage types for user-generated media (UGM): consumption, participation and production. Media use which is limited to watching, reading or viewing behavior is described as consuming usage, the lowest level of interaction. Participation involves basic user-to-user interaction and user-to-content interaction, such as rating content (e.g. "like") and sharing it with others. Also the establishment of a network connection on SNS has been described as participating usage [7]. The highest level of interaction is production, and describes the creation and publication of contents in the form of text, images, audio and video [23].

\section{Literature review: The development of the socio-cognitive model of brand page usage}

The following chapter discusses the theoretical foundation of our three models of brand page usage [8]. Thus, the motivations identified for each usage type will be described in regard to their respective SCT incentive dimensions.

We took on an integrated communication approach [24] to studying brand page behavior. Thus, the development of our models was informed by studies from the field of online marketing [25, 26, 27, 28, 29], as well as rather general Web 2.0 usage motivations [20, $25,30,31,32$ ], which were applied to brand pages. In the following, the SCT dimensions explaining each usage model, as well as the underlying reasons to use corporate pages are italicized.

\subsection{SCT dimensions and usage motives of brand pages on web 2.0 applications}

3.1.1. Consumption motives of corporate pages. Probably of the most popular motivations for brand page usage being addressed in the literature since Facebook opened up its services for corporations in 2007 are concerned with monetary incentives: Studies in the USA and Europe revealed that individuals use corporate pages to look for coupons, discounts and take part in competitions $[2,6,25,26,32]$, or because they want to play a free game on the page $[31,33,34]$.
With the professionalization of brand pages and corporation's increased investment in SNS, studies [6, $7,35]$ found that community members' primary reasons to consume messages on brand pages are to obtain product, service and corporate information (novel incentive), which helps them to form an opinion (selfreactive incentive) about the corporation. During our model development, we found the above motivations to be closely related to users' expectation about the information available on brand pages to be trustworthy (self-reactive incentive), as well as unique to the platform (novel incentive) [7, 21, 25, 29]. Since all these motives loaded on the same factor in our exploratory factor analysis, there seems to be an interaction effect between these variables. Therefore, we conceptualized these motivations as a combined incentive dimension, i.e. self-reactive-novel incentives as motivations relating to a perceived need to acquire new information [8].

The third dimension contains entertainment, relaxation and passing the time motivations to visit a brand profile. Research shows that people prefer to read corporate posts if these are accompanied with pictures, videos or some kind of advertising material [25, 27, 28, $32,33,34,35,36]$. These motives were described as activity incentives in our model. Interestingly, all studies addressing brand page usage on SNS come to the conclusion that individuals use corporate pages predominantly passively by reading or looking at the content available.

3.1.2. Participation motives of corporate pages. On the next higher interaction level, the literature suggests that individuals are likely to connect with ("like") brand pages to primarily serve their image management and self-presentational needs, relating to the status dimension of SCT [2, 7, 8]. Scholars point out that especially young users want to let others know which products and services they use, as well as which products and services suit their lifestyle [8, 26, 27]. Likewise, researchers found that digital natives network with corporations because they think that others will have a positive image of themselves and think of them as being likeable [9].

Next to rather image management centered motives, businesses in the USA and Europe were befriended because people like the corporation (self-reactive incentive), feel close to the corporation (self-reactive incentive) and wish to support a corporation (idealistic incentive) by "liking" their page [2, 6, 7, 25, 27]. In our model, these incentives again described one incentive factor, the self-reactive-idealistic dimension. Thus, self-reactive idealistic motives refer to the perceived personal need to do good or be altruistic [8]. 
A major reason to connect with brand pages is that establishing a network connection automatically results in the following of news updates on the respective brand page. This means that by liking a corporate page, corporate real time information will prospectively appear in one's news feed. Therefore, a brand connection seems to represent a practical way to receive continuous, instant information about the company individuals would not be looking for otherwise. Next to these novel incentives, for some European users liking a corporation seems to equal the motive to keep in touch with an organization in an easy manner (practical motive) [7, 27, 32, 35, 36]. Therefore, these items relate to a combined incentive dimension of selfreactive and idealistic motivations in our model, describing motives which allow the easy and convenient retrieval of new information [8].

\subsubsection{Production motives of corporate pages.} Among the most prominent reasons to produce content on corporate pages is the incentive to inquire specific information from a company. This can either be general (new) product or service information, customer support inquiries or information about the company itself (nonproduct/service-related information) [2, 7, 8]. Furthermore, information exchanges with other users serve as major incentive to post content on corporate pages, i.e. asking questions to the community, commenting/answering questions posed by other users or just engaging in general discussions about the company and its products/services with the community. Likewise, reactions to postings by the company eliciting feedback from the community, also in the form of comments on pictures and video clips are often mentioned interaction motives $[5,6,7,8]$.

The provision of feedback to the company and community, i.e. product reviews, praise and criticism is an objective generally pursued by many users on brand pages $[6,7,8,35]$. Since all feedback has a social character and is intended as stimulus or response for future communication, the above motivations can be described as social incentives in our model.

Production incentives such as public criticism, however, also seems to gratify other, rather selfreactive needs for the community, such as reduce stress and frustration and allow them to feel good/better [5, 20, 30]. Users indicated they feel less inhibited to communicate with corporations on Facebook than through other channels [32], and expect to receive answers more promptly than through other forms of communication [31].

Another incentive dimension relates to incentives of status and social power. User statements on brand pages were found to gratify people's need for public attention [25], as well as the motivation to exert influence on others (community members, the corporation etc.) [6]. People post on a brand page because they want to appear competent [13, 23], and by doing so, express that they are not shy to publicly interact with corporations [31]. No matter what the post is about, users expect public recognition for their posts, be it either from the corporation, other community members, or both $[8,23,25]$.

Overall, studies find that production is the least frequently used type of usage on the continuum. Most users' engagement with brand pages does not exceed participation $[6,7,8]$.

The above discussion of the literature raises the question if the three usage models we derived in an earlier study [8] can be confirmed with a new dataset in this study. Therefore, our research question is: How well do the three socio-cognitive models for brand page usage fit the data obtained in this study?

Further, the conceptualization of our models allow us to address the following hypotheses:

Hypothesis 1: The usage model for consumption can be explained by a three factor model consisting of activity, self-reactive-novel and monetary incentives.

Hypothesis 2: The usage model for participation can be explained by a three factor model consisting of status, practical-novel and self-reactive-idealistic incentives.

Hypothesis 3: The usage model for production can be explained by a three factor model consisting of social, self-reactive and status incentives.

\section{Method}

To answer our research question and the underlying hypotheses, we conducted an online-survey in corporation with the biggest corporations headquartered in [place withheld for review]. On the basis of a publicly available company listing [41], the Facebook profiles of the top 150 corporations were examined. Only such companies with brand pages being followed by at least 100,000 people were included in our sample. The corporations were contacted for participation in our study and in total, nine companies were interested to participate.

The data for our study was obtained through an online survey using the quantitative web survey application LimeSurvey. All participating corporations received an individual survey URL to be able to differentiate the results among the companies later. The respective survey URLs were posted on the different brand 
pages by the corporations themselves, inviting their community members to participate. Data collection took place between mid-June and mid-September 2015. Each corporation decided how frequently it would display the survey on their Facebook page.

At the beginning of the survey, participants were asked four filter questions to determine how often they use Facebook in general, how often they read corporate posts on Facebook, how often they "like" corporations on Facebook, and how often they make postings on brand pages. Answer possibilities included "once or several times a day", "once or several times a week", once or several times a year", less than once a year, and "never". In case respondents indicated that they "liked" brand pages on Facebook, they were also asked to estimate the amount of corporations, they are connected with. News pages, such as Euronews, CNN news, BBC News etc. were excluded from the investigation.

Once all filter questions were answered, participants were directed to the respective question blocks applying to their specific user type(s). Questions about the incentives for brand page consumption, participation and production were measured using a 7-point Likert scale ranging from (1) strongly disagree to (7) strongly agree. The questions were formulated using SCT question wording [12] to have people indicate the likelihood to which they expected a certain outcome to motivate their use of corporate Facebook pages, i.e.: "When I read postings of corporations on Facebook, it is likely that..." (consumption), "When I 'like' corporations on Facebook, it is likely that..." (participation), and "When I write a post or comment on a corporate Facebook page, it is likely that..." (production). At the end of the survey, respondents were asked to indicate some basic demographic data.

All response data was analyzed in regard to the usage behavior indicated by the participants. For each usage type, the response data was analyzed using exploratory factor analysis in SPSS 23 to cross-check the existence of the same factor-solution put forward in our socio-cognitive models for brand page usage [8], before applying confirmatory factor analysis with AMOS 23 for model assessment.

\section{Results}

In total, $1294\left(\mathrm{~N} ; \mathrm{n}_{\mathrm{female}}=493, \mathrm{n}_{\text {male }}=801\right)$ valid datasets were obtained from the online-survey. Initial data analysis revealed that 1151 persons $(88.9 \%$,) consume corporate pages, 1099 persons $(84.9 \%)$ participate with brands, and 913 persons $(70.6 \%)$ have already posted content on corporate pages. On average, respondents use Facebook between half an hour and one hour a day and read corporate pages several times a week. The average brand page user was 39 years old, connected with 37 corporations, indicated to click the "like" button on brand pages once or several times per month, and produces content on brand pages once or several times a year.

All item distributions were assessed and items exceeding a skewness value of one were log transformed to be suitable for further statistical testing.

\subsection{EFA for model confirmation in the dataset}

Exploratory factor analysis (Maximum-Likelihood method with Varimax rotation and extraction criteria of eigenvalue $>1.0$ for consumption and participation; set number of three factors to be extracted for production model) confirmed the three factor models for participation and production in the data set.

However, the model for consumption suggests a slight modification of the item structure in regard to their incentive dimensions: The item pictures and videos seems to be better suited among the self-reactivenovel incentive dimension (factor loading .55) than among the activity dimension (factor loading .23). With this alteration, all extracted factors still show good Cronbach's Alpha values of .8 and above. The reassignment of the motivation to look at corporate pictures and video clips on a corporate page is still well compatible with the self-reactive-novel dimension of SCT. The latter describes motivations which allow people to learn something new, and since users like posts about corporate products and services to be accompanied by pictures [7], it seems reasonable to reassign the motive to the self-reactive-novel dimension.

\subsection{CFA results for model assessment}

After the EFA confirmed the existence of our hypothesized factor models in the dataset, we applied confirmatory factor analysis to test how well the data fits our three usage models. In the following sections, we will describe the model fit for each user type.

5.2.1. Results and assessment of the factor model for consuming usage. The initial CFA for the three factor model describing consumption behavior on brand pages resulted in a null (default) model with 37 degrees of freedom (DF) and a significant chi $^{2}$-value (244.243), meaning that other models might explain the data just as well as our model does (see table 1 in appendix). Still, the adjusted goodness-of-fit index (AG- 
FI) which measures the amount of variance and covariance (including DF) in the sample data that is jointly explained by the model shows an acceptable value of .936 (should be $\geq .9$ ). The expected cross validation index (ECVI), which assesses the likelihood that the model will cross-validate in other similar sized samples from the same population is higher (.263) than the same index for the saturated model (.115), as well as lower that the value for the independence model (5.166). Since ECVI values can take any form, default model values lower than the respective values for the saturated and independence model are generally accepted as good values [37]. Finally, the root mean square error of approximation (RMSEA), which assesses how well the model fits the real population covariance matrix if it was available, can be deemed reasonable at a value of .070 (should be $\leq .06$ for good fit). Thus, it is necessary to further fit the model in regard to the data.

5.2.2. Model modification for consuming usage. The first step to further adapt the model is to exclude items with very low factor loadings of $\leq .6$ from our analysis and reassess the resulting model fit indices and factor loadings for the nested model (table 1). This results in a model with $22 \mathrm{DF}$ and a still significant chi $^{2}$-value of 112.93 , yet indicating a better sample fit than the null model. Also the AGFI value positively increased to .958 . The ECVI value for our default model (.138) is still higher than the respective value for the saturated model (.078), however the difference between the two models has decreased. Also RMSEA has decreased to a good fit value of .060 , suggesting the nested model fits our sample data much better than the null model.

The items with the highest factor loadings are to take part in a competition (.92) among the monetary incentive dimension, to form an opinion about the products and services of an organization among the self-reactive-novel dimension (.90), as well as to feel entertained (.89) among the activity dimension (see table 2 in appendix). Therefore, we can conclude that our suggested theoretical usage model for consuming usage has been validated with our sample data (hypothesis 1 accepted).

5.2.3. Results and assessment of the factor model for participating usage. The CFA for the suggested model describing participating usage of brand pages results in a null model with $38 \mathrm{DF}$ and a significant chi $^{2}$-value of 290.665. With .921, AGFI already indicates good model fit. Likewise, the ECVI value of our default model (.321) is slightly higher than the one of the saturated model (.122), however far distant from the independence model (6.127). Therefore, the null model's AGFI and ECVI values can be deemed reasonable. However, the null model's RMSEA value of .078 indicates poor fit (see table 3 in appendix), pointing to the fact that we will need to specify our model.

5.2.4. Model modification for participating usage. Applying the same modification approach as to the model for consumption, we deleted all items with low factor loadings of $\leq .7$ from the model.

The resulting model fit with $14 \mathrm{DF}$ and a significant chi $^{2}$-value of 67.36 already indicates a better fit to the sample than the null model. The AGFI value increases to .961 and the ECVI value decreases to (.103). Yet, the latter again remains higher than the respective value for the saturated model (.067), but much lower than for the independent model (4.069). Again, the difference in ECVI values between the default and the saturated model has decreased (see table 3 in appendix).

Our alterations have also positively affected the RMSEA, which decreased to a good fit value of .059. The above data suggests that the nested model fits our sample data much better than the null model.

The usage motivations for participation which have the highest factor loadings among the status incentives are products and services suit my lifestyle, as well the need to show which products and services one uses, which show similar loadings of .89 and .91 respectively (see table 4 in appendix). Among the practical-novel dimension, the two motivations receive corporate realtime information without active searching and to receive information one would not be looking for otherwise both have high loadings of .87. Finally, the item which loads highest on the self-reactive-idealistic dimension is the reason to just like a corporation (.80).

In regard to hypothesis 2, we find the usage model for brand page participation describing status, practicalnovel and self-reactive idealistic incentives to drive networking to hold in our sample data (hypothesis 2 accepted).

5.2.5. Results and assessment of the factor model for production usage. The three factor model for the most interactive brand page usage results in a null model with $59 \mathrm{DF}$ and a significant chi $^{2}$-value of 430.492. Both, the AGFI (.643) as well as the RMSEA (.083) shows a bad model fit (see table 5 in appendix). Also the ECVI value for the default model (.542) is not lower than the values for the saturated (.200) and independent model (7.797). 
5.2.6. Model modification for production usage. Two items applied in the CFA did not yield sufficiently high loadings of $>.6$. These are the items I request concrete information from the company on the social dimension, as well as $I$ expect to receive a prompt answer among the self-reactive incentives. Therefore, these items were excluded from the analysis in the next step of further model modification.

Erasing these items from the analysis results in a better, yet not satisfying model fit. Therefore, the modification indices were consulted. The latter indicated a correlation between the error terms of the items to provide feedback to the corporation and to react to corporate posts among the social dimension. We allowed the error terms of these two items to correlate and further deleted one item from the status incentives in order to keep the amount of items per factor rather equal. We chose the item to influence others to be dropped from further analysis since this item had the lowest factor loading (.71) among the status dimension.

The resulting nested model shows a much lower number of $28 \mathrm{DF}$, yet, the chi-square value of 94.592 remains significant. The nested model also explained a higher amount of the (co-)variance with respect to DF than the null model (AGFI=.960), as well as an acceptable ECVI fit of .163, being slightly higher than the respective value for the saturated model (.121) and much lower than the ECVI of the independence model (6.074) value. In addition, RMSEA (.051) indicates excellent model fit (see table 5 in appendix).

Due to the correlation of error terms (.39) between two variables, their factor loadings dropped from .70 to .54 (feedback to corporation) and .80 to .64 (react to corporate post).

All remaining items show factor loadings of $\geq .73$. Among the social dimension, the motivation to exchange with other users has the highest factor loading (.90). The highest factor loadings among the selfreactive (feel better) and status incentives (catch other's attention) are slightly lower with .87 (see table 6 in appendix). After fitting the model for production usage, it can be concluded that our third hypothesis is also supported by the sample data.

\section{Discussion}

\subsection{Summary}

In this study, we tested three models for Facebook brand page usage, which had been developed in previous exploratory research [8]. The models build on a combined perspective of U\&G and SCT, which allows us to investigate the incentives of Web 2.0 community members to use corporate Facebook pages. Our literature review analyzed the motives for consuming, participating and producing brand page usage from an integrative perspective [24]. We further explained how the motivations informed the development of our models.

The results of our online survey $(\mathrm{N}=1294)$ show that the hypotheses put forward in this study are supported: Consumption behavior on corporate pages is driven by a combination of activity incentives, selfreactive-novel incentives and monetary incentives. Status incentives drive participation on brand pages, followed by practical- novel incentives and selfreactive incentives. Finally, production behavior can be explained by a combination of social, self-reactive and status incentives. All default models were slightly adjusted to better fit the sample data. All nested models yielded (very) good values among the most commonly addressed fit indices (AGFI, RMSEA, ECVI), which points to the explanatory power of our model for the study of brand page behavior.

\subsection{Limitations and future research}

None of the tested models for brand page usage in this study showed a non-significant $\mathrm{chi}^{2}$-value. Even though this theoretically suggests that other models might explain the data just as well as our model does, it has often been noted that $\mathrm{chi}^{2}$-values are sensitive to sample size $[37,38]$. Since large samples are known to have a negative impact on this measure, we relied first and foremost on other established measures for model assessment.

This study explored the motivations for brand page usage at the earliest stage in the continuum of web 2.0 usage, at which a respective brand page behavior is expected to occur based on a pre-study [8]. Therefore, future studies should investigate if certain incentives dimensions, such as monetary incentives, might also motivate participation of production behavior.

Another limitation applies to the data collection: Since every corporation decided itself, how often they posted the survey link on their brand page, the sample might be biased with respect to certain industries, whose followers are more likely to participate than the users of another industry in the sample. Therefore, our sample can neither be deemed representative for a certain industry in Switzerland, nor for brand page usage in general.

In regard to other existing studies addressing brand page behavior $[2,6,7]$ the sample applied in this study can be described as consisting of highly active brand 
page users. The data indicates that $70 \%$ of all participants produce content on corporate Facebook pages. This might be due to the respondent's self-selectivity in deciding whether or not to participate in the study when reading about it on a corporate brand page.

Furthermore, our study results are generally in line with the research findings of the few recipient-oriented social media PR studies conducted in the past. Yet, our investigation embedded the gratifications which were rather loosely investigated in the past in a theoreticallytested model of brand page usage.

One could argue that the level to which a person feels close to, or identifies with a corporation might have an impact on the respondents' willingness to participate in the survey. Therefore, future research should investigate possible antecedents which might have an effect on people's brand page behavior before the motivations addressed in this study actually come into play. In addition, different personality types might have an impact on the community members' use of corporate offerings on SNS. Also, research suggests that culture might have an effect on the individuals' incentives of brand page usage. Future research should therefore apply the proposed model to a variety of cultural settings to further investigate its explanatory power and help us better understand SNS brand community behavior.

\subsection{Implications for community management on corporate Facebook pages}

Our results point to a number of implications for effective community management on Facebook brand pages. First, the high number of respondents in this study points to the fact that company pages seem to be relevant communication outlets for the stakeholder community and pose meaningful channels for community management.

To effectively manage one's community on Facebook, it is important to provide users with entertaining and fun information about the corporation's products and services, as well as offer competitions or other financial benefits such as vouchers.

Status incentives and the need to manage one's personality online indicate the willingness of users to "like" a corporation on Facebook. Therefore, a positive corporate reputation might have a positive effect on community size and even result in the community's support of the corporation because people feel close to it (self-reactive-idealistic incentives). In addition, it seems as if the mere provision of continuous corporate information can already help to keep the community happy by gratifying their practical-novel incentives to receive corporate updates in an easy manner.

The community's incentives to interact with other users and the company on a brand page requires careful attention of the people managing the brand page to closely assess when company involvement is needed and when the page provides a mere platform for community exchange. Once addressed directly, users expect corporations to appreciate their contributions on the page. However, users aim not only to catch the corporation's, but also other users' attention with their posts. Arguably, this holds especially true in situations in which users seek to complain about a company's products or services.

\section{References}

[1] D.M. Boyd, N.B. Ellison, "Social network sites: definition, history, and scholarship", IEEE Engineering Management Review, 3(38), 2010, 16-31.

[2] M. Vorvoreanu, "Perceptions of corporations on Facebook: An analysis of Facebook social norms", Journal of New Communication Research, 2009, 67-86.

[3] J. R. Gusfield, "The community: A critical response", Harper Colophon, New York, 1975.

[4] E. Durkheim, "The division of labor in society", Free Press of Glencoe, New York, 1964.

[5] L.R. Men, W.-H.S. Tsai, "How companies cultivate relationships with publics on social network sites: Evidence from China and the United States", Public Relations Review, 2012, 723-730.

[6] L.R. Men, W.-H.S. Tsai, C. "Beyond liking or following: Understanding public engagement on social networking sites in China", Public Relations Review, 2013, 13-22.

[7] C. H. Ruehl, D. Ingenhoff, "Communication Management on Social Networking Sites", Journal of Communication Management, 2015, 288-302.

[8] C. H. Ruehl, D. Ingenhoff, "Community Management on Social Networks: Why and How Stakeholders Use Corporate Facebook Pages", paper presented at the $49^{\text {th }}$ HICSS Conference, Koloa, HI, USA, January 4-7, 2016.

[9] J.E. Blumler, E. Katz, The uses of mass communications. Current perspectives on gratifications research, Sage, Beverly Hills/London, 1974.

[10] A. Bandura, Social foundations of thought and action. A social-cognitive theory, Prentice Hall, Englewood Cliffs, 1986.

[11] R.L. LaRose, D. Mastro, M.S. Eastin, "Understanding internet usage: A social-cognitive approach to uses and gratifications", Social Science Computer Review, 2001, 395-413.

[12] R. LaRose, M.S. Eastin, "A social cognitive theory of internet uses and gratifications: Toward a new model of media attendance", Journal of Broadcasting \& Electronic Media, 2004, 358-377.

[13] K.E. Rosengren, Uses and gratifications: A paradigm outlined, in: J.E. Blumler, E. Katz (Eds.) The uses of mass 
communications. Current perspectives on gratifications research, Sage, Beverly Hills/London, 1974, pp. 269-286.

[14] B.S. Greenberg, Gratifications of television viewing and their correlates for British children, in: J.E. Blumler, E. Katz (Eds.) The uses of mass communication. current perspectives on gratifications research, Sage, Beverly Hills/London, 1974, pp. 71-92.

[15] P. Palmgreen, J.D. Rayburn II, "Gratifications sought and media exposure: An expectancy value model", Communication Research, 1982, 561-580.

[16] D.P. Ferguson, E.M. Perse, "The world wide web as a functional alternative to television", Journal of Broadcasting \& Electronic Media, 2000, 155-174.

[17] Z. Papacharissi, A.M. Rubin, "Predictors of internet usage", Journal of Broadcasting \& Electronic Media, 2000, 175-196.

[18] B.J. Parker, R.E. Plank, "A uses and gratifications perspective on the internet as a new information source", American Business Review, 2000, 43-49.

[19] A. M. Rubin, Uses and Gratifications. An Evolving Perspective of Media Effects, in: R. L. Nabi, M. B. Oliver (Eds.) The Sage Handbook of Media Processes and Effects, Sage, Thousand Oaks, 2009, pp. 147-59.

[20] C. Jers, Konsumieren, partizipieren und produzieren im Web 2.0. Ein sozial-kognitives Modell zur Erklärung der Nutzeraktivität, Herbert von Halem Verlag, Köln, 2012.

[21] W.-H. S., Tsai, L. R. Men, "Motivations and antecedents of consumer engagement with brand pages on social networking sites", Journal of Interactive Advertising, 2013, 76-87.

[22] A. Lovari, L. Parisi, "Listening to digital publics. Investigating citizens' voices and engagement within Italian municipalities' Facebook Pages", Public Relations Review, 2015, 205-213.

[23] G. Shao, "Understanding the appeal of user-generated media: a uses and gratification perspective", Internet Research, 2009, 7-25.

[24] M. Bruhn, Planning integrated marketing communications, in: H. Sievert, D. Bell (Eds.), Communication and leadership in the $21^{\text {st }}$ century, Bertelsmann Stiftung, Gutersloh, 2008, pp. 13-34.

[25] R. Davis, I. Piven, M. Breazeale, "Conceptualizing the brand in social media community: The five sources model", Journal of retailing and consumer services, 2014, 468-481.

[26] E. Enginkaya, H. Yilmaz, "What drives consumers to interact with brands through social media?, Precedia - Social and Behavioral Sciences, 2014, 219-226.

[27] B. Jahn, W. Kunz, "How to transform consumers into fans of your brand", Journal of Service Management, 2012, 344-361.

\section{Appendices}

The appendix shown below has been shortened to comply with the publication guidelines provided by HICSS. Therefore, only the CFA solutions for the nested models (tables 2, 4 and 6) are included here. You can download the full appendix at goo.gl/4wHk59.
[28] S. Nambisan, R. A. Baron, "Interactions in virtual customer environments: Implication for product support and customer relationship management. Journal of Interactive Marketing, 2007.

[29] N. Singh, K. Lehnert, K. Bostick, "Global Social Media Usage: Insights Into Reaching Consumers Worldwide. Thunderbird International Business Review, 2012, 683-700.

[30] A. Nadkarni, S.G. Hofmann, "Why do people use Facebook?", Personality and Individual Differences, 2012, 243249.

[31] P. Pai, D.C. Arnott, "User adoption of social networking sites: Eliciting uses and gratifications through a means-end approach", Computers in Human Behavior, 2013, 1039-1053.

[32] A. Quan-Haase, A.L. Young, "Uses and gratifications of social media: A comparison of Facebook and instant messaging", Bulletin of Science, Technology \& Society, 2010, 350361.

[33] H. Bicen, N. Cavus, "Social network sites usage habits of undergraduate students: case study of Facebook". Procedia - Social and Behavioral Sciences, 2011, 943-947.

[34] C. M. K. Cheung, P.-Y. Chiu, M. K. O. Lee, "Online social networks: Why do students use Facebook? " Computers in Human Behavior, 2011, 1337-1343.

[35] E. Enginkaya, H. Y1lmaz, "What drives consumers to interact with brands through social media? A motivation scale development study", Precedia - Social and Behavioral Sciences, 2014, 219-226.

[36] S. K. Foregger, Uses and gratifications of Facebook.com, ProQuest, Ann Arbor, 2008.

[37] B. M. Byrne, Structural equation modeling with AMOS, Routledge, New York, 2009.

[38] R. B. Kline, Principles and practice of structural equation modeling, The Guilford Press, New York, 2011.

[39] M. R. Habibi, M. Laroche, \& M.-O. Richard. "Testing an extended model of consumer behavior in the context of social media-based brand communities". Computers in Human Behavior, 62, 2016, 292-302.

[40] P. Kaur, A. Dhir, \& R. Rajala. "Assessing flow experience in social networking site based brand communities". Computers in Human Behavior, 64, 2016, 217-225.

[41] Handelszeitung, Top 500. Die grössten Unternehmen der Schweiz 2014, Ringier, Zurich, 2015.

[42] T. E. Ruggiero,). "Uses and gratifications theory in the 21 st century", Mass communication \& society, 3(1), 2000, 337. 
Table 2: Standardized solutions by CFA for the nested three factor model for consuming usage

\begin{tabular}{|c|c|c|c|}
\hline \multirow[t]{3}{*}{ Item (expected outcome) } & \multicolumn{3}{|l|}{ Factor } \\
\hline & 1 & 2 & 3 \\
\hline & Activity & $\begin{array}{l}\text { Self-reactive } \\
\text { novel }\end{array}$ & Monetary \\
\hline ...I want to feel entertained & .89 & & \\
\hline ...I want to have fun. & .86 & & \\
\hline ...I want to pass time. & .65 & & \\
\hline $\begin{array}{l}\text {...I want to form an opinion about a corporation's products and ser- } \\
\text { vices. }\end{array}$ & & .90 & \\
\hline ...I want to form a general opinion about the corporation. & & .84 & \\
\hline ...I want to find information I can trust. & & .61 & \\
\hline ...I want to play a game or quiz for free. & & & .68 \\
\hline $\begin{array}{l}\text {...I want to receive vouchers, discount coupons or special offers for } \\
\text { products and services. }\end{array}$ & & & .80 \\
\hline ...I want to take part in a competition. & & & .92 \\
\hline
\end{tabular}

Table 4: Standardized solutions by CFA for the nested three factor model for participating usage

\begin{tabular}{|c|c|c|c|}
\hline \multirow[t]{3}{*}{ Item (expected outcome) } & \multicolumn{3}{|l|}{ Factor } \\
\hline & 1 & 2 & 3 \\
\hline & Status & $\begin{array}{l}\text { Practical- } \\
\text { novel }\end{array}$ & $\begin{array}{l}\text { Self- } \\
\text { reactive }\end{array}$ \\
\hline ...I want to let others know which products and services suit my lifestyle. & .89 & & \\
\hline ...I want to let others know which products and services I buy. & .91 & & \\
\hline ...I want to have new corporate posts appear in my news feed. & & .70 & \\
\hline ...I want to receive real-time information from corporations. & & .87 & \\
\hline $\begin{array}{l}\text {...I want to keep updated on news about the corporation, which I would } \\
\text { not be looking for otherwise. }\end{array}$ & & .87 & \\
\hline ...I feel close to the corporation & & & .77 \\
\hline ...I like the corporation/think of it as being sympathetic & & & .80 \\
\hline ...I want to support the corporation. & & & .75 \\
\hline
\end{tabular}

Table 6: Standardized solutions by CFA for the nested three factor model for production usage

\begin{tabular}{|c|c|c|c|}
\hline \multirow[t]{3}{*}{ Item (expected outcome) } & \multicolumn{3}{|l|}{ Factor } \\
\hline & 1 & 2 & 3 \\
\hline & Social & Self-reactive & Status \\
\hline ...I provide feedback about a corporation's the products and services & .54 & & \\
\hline ...I react to the posts of corporations (statements, questions etc.) & .64 & & \\
\hline ...I exchange opinions/views/information with other users. & .90 & & \\
\hline ...I reduce strain and stress/frustration. & & .85 & \\
\hline ...I feel good/better by doing so. & & .87 & \\
\hline ...I feel less inhibited to contact a corporation on Facebook & & .73 & \\
\hline ...I want to catch other people's attention. & & & .87 \\
\hline ...I want my posts to be appreciated by others. & & & .74 \\
\hline ...I want others to think I am a competent person. & & & .83 \\
\hline $\begin{array}{l}\text {...I want to show others that I am not shy to publicly communicate } \\
\text { with corporations. }\end{array}$ & & & .75 \\
\hline
\end{tabular}

